\title{
PENGEMBANGAN SELF-HELP BOOK UNTUK MEMBANTU PESERTA DIDIK MENGATASI KONFLIK DENGAN ORANG TUA DALAM PERSPEKTIF KONSELING REALITAS
}

\author{
Hilma Fitriyani ${ }^{1}$ \\ Diana Syamila ${ }^{2}$
}

\begin{abstract}
Abstrak
Penelitian ini bertujuan untuk menghasilkan media pembelajaran self-help book (buku bantuan diri) mengenai cara mengatasi konflik dengan orang tua dalam perspektif terapi realitas yang ditujukan kepada kelas X dan XI jurusan IPS di SMA Suluh Jakarta. Metode penelitian yang digunakan merupakan metode Research and Development $(\mathrm{RnD})$ dengan menggunakan model ADDIE (Analyze, Design, Develop, Implement, Evaluate). Tahapan model pengembangan yang dilakukan dalam penelitian ini adalah analisis, desain, dan pengembangan. Evaluasi formatif dilakukan oleh validator ahli media, ahli materi, da peserta didik. Berdasarkan data tersebut menunjukkan hasil evaluasi validitas ahli media $82,9 \%$ (baik), validitas ahli materi $88,6 \%$ (sangat baik), dan peserta didik $91 \%$ (sangat baik). Hasil penelitian adalah sebuah buku yang berisi tahapan penyelesaian konflik dengan orang tua menggunakan sistem WDEP pada perspektif terapi realitas.
\end{abstract}

Kata Kunci: Pengembangan, Model ADDIE, Self-Help Book, Terapi Realitas, Konflik Orang Tua-Remaja.

\begin{abstract}
This study aims to produce an instructional book about steps to resolve conflict with parents for 10th and 11th grader of Suluh High School Jakarta. The research method used is the Research and Development (R\&D) method using the ADDIE (Analyze, Design, Develop, Implement, Evaluate) model. The stages of the development model in this research are in analysis, design, and development. Formative evaluations had been done by a media expert validation evaluation $82,9 \%$ (good), validity of material experts $88,8 \%$ (very good), and students $91 \%$ (very good). The results of the study are a book that contains stages of resolving conflicts with parents using the WDEP system in the perspective of reality therapy.
\end{abstract}

Keywords: Development, ADDIE model, Self-Help Book, Reality Therapy, Parents-Adolescents Conflict.

\section{PENDAHULUAN}

Masa remaja merupakan masa transisi dimana peserta didik mulai mengalami perkembangan yang pesat pada berbagai aspek, salah satunya aspek kognitif. Pada

\footnotetext{
${ }^{1}$ Universitas Negeri Jakarta, hilma@unj.ac.id

${ }^{2}$ Universitas Negeri Jakarta, dianasyamila@gmail.com
}

usia ini, kemampuan remaja dalam berpikir dan mengambil keputusan sendiri semakin berkembang (Deutsch, Coleman, \& Marcus, 2016). Hal tersebut dapat menjadi penyebab ketegangan yang terjadi remaja dengan orang tua melalui perilaku menentang dan 
menuntut kebebasan dari orang tua (Allison, 2000).

Menurut Allison (2000), konflik antara orang tua dan remaja meningkat selama tahun-tahun sekolah menengah dan melibatkan peristiwa sehari-hari di dalam keluarga yang menurut Elkind (Frydenberg, 2002) dimulai pada usia 15 tahun. Konflik dalam hubungan dekat seperti hubungan di dalam keluarga tidak dapat terhindarkan. Menurut Dwyer (Lestari, 2012), semakin tinggi ketergantungannya semakin meningkat pula kemungkinan terjadinya konflik.

Konflik yang terjadi di dalam hubungan keluarga dapat bermanfaat atau merugikan tergantung strategi yang digunakan untuk menyelesaikannya. Apabila dikelola secara konstruktif akan mengukuhkan hubungan, namun sebaliknya konflik yang dalam penanganannya destruktif dapat merusak hubungan dan memunculkan emosi negatif yang kemudian membuat masalah terjadi berulang-ulang (Lestari, 2012).

Dampak dari konflik bagi remaja apabila dalam penanganannya destruktif adalah stres, depresi, dan rendahnya kepercayaan diri (Razali, 2013). Hal tersebut kemudian akan berdampak pada kesulitan remaja dalam mengatasi masalah yang mengakibatkan harga diri dan motivasi belajar menurun.

Hasil studi pendahuluan yang peneliti lakukan di SMA Suluh Jakarta memiliki hasil bahwa sebanyak 136 dari 310 peserta didik (45\%) mengalami konflik dengan orang tua. Namun, berdasarkan hasil wawancara yang dilakukan dengan guru BK menerangkan bahwa topik tentang konflik dengan orang tua belum pernah disampaikan. Padahal, kasus yang diterima guru BK didominasi oleh peserta didik yang mengalami konflik dengan orang tua.

Sejauh ini, intervensi yang dilakukan guru BK dalam menangani kasus peserta didik yang mengalami konflik dengan orang tua adalah dengan konseling berkala dengan menghadirkan pihak lain seperti wali kelas, kesiswaan, dan wali murid apabila diperlukan tanpa menggunakan media sebagai penunjang pelaksaaan konseling.

Dengan demikian, perlu adanya pengembangan media untuk menangani kasus konflik dengan orang tua bagi remaja melihat bahwa guru BK dalam memberikan layanan di sekolah mengacu pada aspek pekembangan yang berada pada Standar Kompetensi Kemandirian Peserta Didik (SKKPD) pada aspek kematangan emosi, yaitu mempelajari cara-cara pengambilan keputusan dan pemecahan masalah secara objektif. Sehingga, Pengembangan media ini akan menunjang pemberian layanan responsif berupa kegiatan konseling individu atau konseling kelompok.

Studi pendahuluan menunjukkan bahwa sebanyak 244 peserta didik (79\%) menyatakan bahwa guru BK menggunakan LKS dan buku cetak sebagai media dalam menyampaikan materi. Sehingga, media berupa self-help book yang berisi tahaptahap penyelesaian disertai latihan-latihan di dalamnya dapat mudah diterima oleh peserta didik sebagai media pembelajaran tertulis.

Self-help book sebagai media memiliki pengertian yang berangkat dari self-help; bantuan diri yang berarti tindakan membantu diri sendiri dalam bentuk buku. Dalam pengembangannya self-help book menggunakan perspektif realitas yang memiliki keterkaitan bahwa peserta didik memiliki kontrol dan tanggungjawab penuh atas dirinya sendiri (Corey, 2013).

Media self-help book yang akan dikembangkan berisi tahapan penyelesaian dengan menggunakan sistem WDEP sebagai dasar pengembangan. Setiap bab pada konten self-help book merepresentasikan setiap akronim dari WDEP.

\section{Self-Help Book}

Bergsma (2007) menjelaskan bahwa self-help book memiliki pengertian yang berangkat dari self-help, yaitu bantuan diri berupa tindakan membantu atau memperbaiki diri sendiri tanpa bantuan orang lain. Self-help book selalu memiliki pendahuluan di halaman pertama dan 
beberapa ketentuan yang dapat membedakannya dari buku-buku lain.

Kelebihan pada self-help book berupa: (1) harga yang lebih murah daripada biaya konsultasi dengan psikolog; (2) mudah digunakan kapan saja dan dimana saja; (3) kerahasiaan permasalahan terjamin; (4) dapat digunakan secara mandiri terutama bagi individu yang tidak berani atau malu mengungkapkan sesuatu (Bergsma, 2007).

\section{Perspektif Realitas}

Terapi realitas mengacu pada paham dasar bahwa individu memilih perilakunya sendiri, sehingga individu bertanggung jawab bukan hanya terhadap apa yang dilakukan, tetapi apa yang dipikir (Gunarsa, 2012). Sehingga, terapi realitas memiliki fokus pada tingkah laku sekarang yang pelaksanaannya berupa modifikasi tingkah laku (Corey, 2013).

Melalui perspektif realitas, pengembangan self-help book menggunakan sistem WDEP sebagai tahapan penyelesaian konflik dengan orang tua bagi remaja. Peserta didik akan diajak menentukan tujuan (Want), mengidentifikasi tindakan yang dimiliki (Do), mengevaluasi tindakan yang dimiliki (Evaluation), dan membuat perencanaan tindakan yang efektif (Plan).

\section{Konflik Orang Tua-Remaja}

Konflik di dalam keluarga dapat terjadi karena adanya perilaku oposisi atau ketidaksetujuan antara anggota keluarga, sehingga yang menjadi sumber utama konflik pada umumnya adalah ketidakcocokan antara perspektif anak dan orang tua (Lestari, 2012).

Awal remaja, khususnya pada usia 1015 tahun telah dikaitkan dengan kemunculan eskalasi konflik antara remaja dengan orang tua (Allison, 2000). Namun, sebagian besar penelitian menunjukkan, meskipun ada pola interaksi yang berubah, hubungan dengan orang tua tetap menjadi sumber sosial dan emosional yang penting bagi kehidupan anak-anak, sehingga tidak ada aspek yang lebih penting dari perkembangan remaja yang membahas tentang hubungan remaja dengan orang tua (Lerner \& Steinberg, 2009).

Perspektif realitas menunjukkan bahwa penting bagi peserta didik memiliki hubunga baik dengan orang tua (Corey, 2013). Maka, dengan terjadinya konflik yang dialami remaja dengan orang tua, perspektif realitas akan mendorong remaja untuk menilai dan mengevaluasi perilaku yang dimiliki dalam menghadapi konflik dengan orang tua.

Glasser (Palmer, 2011) menyatakan bahwa semua masalah jangka panjang manusia pada intinya adalah masalah relasi, sehingga konselor membantu peserta didik mengeksplorasi relasi-relasi yang signifikan. Relasi signifikan yang dimiliki peserta didik salah satunya adalah keluarga. Sedangkan, menurut Dwyer (Lestari, 2012) hubungan dekat seperti di dalam keluarga rentan mengalami konflik. Sehingga, konflik di dalam keluarga pasti akan dialami setiap peserta didik dan dapat bermanfaat atau merugikan tergantung strategi yang digunakan untuk menyelesaikannya.

\section{METODE PENELITIAN}

Metode penelitian yang digunakan adalah penelitian dan pengembangan yang menurut Borg dan Gall disebut R\&D (Research and Development). Sugiyono (2014) berpendapat bahwa penelitian dan pengembangan adalah metode penelitian yang digunakan untuk menghasilkan produk tertentu, dan menguji keefektifan produk tersebut.

Selain menggunakan metode $R \& D$, penelitian ini juga menggunakan model ADDIE sebagai tahapan pengembangan media. ADDIE merupakan model pembelajaran yang memiliki pendekatan sistem yang efektif dan efisien serta prosesnya bersifat interaktif untuk menghasilkan sebuah produk (Branch, 2009).

Populasi dalam penelitian ini ditentukan atas rekomendasi guru BK, yaitu peserta didik kelas X dan XI jurusan IPS di SMA 
Suluh Jakarta sebanyak 310. Dari jumlah populasi tersebut, peneliti memperoleh 136 peserta didik yang mengalami konflik dengan orang tua melalui proses identifikasi lebih lanjut dengan ketentuan tertentu. Teknik sampling yang dipilih adalah purposive sampling yang merupakan teknik pengambilan sampel sumber data dengan pertimbangan tertentu (Sugiyono, 2017).

Penelitian ini dilakukan di SMA Suluh Jakarta dan waktu penelitian dilakukan pada bulan Oktober 2017-Juli 2018. Uji coba produk pada penelitian ini melibatkan beberapa responden seperti ahli media, ahli materi, dan peserta didik untuk melihat kelayakan produk yang dikembangkan. Teknik pengambilan data menggunakan instrumen kuesioner yang akan divalidasi secara internal oleh ahli. Namun demikian, pada tahapannya peneliti tidak dapat melakukan uji coba pilot kepada peserta didik melihat bahwa media yang dikembangkan akan memerlukan waktu yang banyak dalam penerapannya sedangkan peneliti memiliki waktu yang terbatas.

\section{HASIL PENELITIAN}

Adapun hasil dari penelitian pengembangan media self-help book ini merujuk pada model ADDIE (Branch, 2009) yang hanya sampai pada tahap pengembangan (Development), yaitu:

Tahap analisis, yaitu mengidentifikasi kesenjangan antara keadaan yang seharusnya dengan keadaan yang sebenarnya, menentukan tujuan instruksional yang akan dicapai, menganalisis karakteristik pengguna media, dan menganalisis sumber daya yang dibutuhkan dalam melaksanakan pengembangan.

Tahap desain, yaitu melakukan rancangan konten dan bentuk media yang akan dikembangkan serta menganalisis instrumen tes yang tepat untuk mengevaluasi produk. Tahap ini peneliti melakukan inventarisasi tugas, menuliskan tujuan mencapai kinerja melalui pembuatan soal, dan melakukan strategi pengujian produk yaitu dengan merumuskan jawaban yang diperlukan untuk mencapai kinerja tersebut.

Tahap pengembangan, yaitu dengan melakukan pengembangan konten, memilih media pendukung, mengembangkan petunjuk penggunaan produk, dan melakukan evaluasi formatif.

Hasil dari tahap pengembangan adalah evaluasi formatif berdasarkan hasil uji coba para ahli yaitu ahli media dan ahli materi. Hasil uji coba ahli media diperoleh persentase sebesar $82,9 \%$ (tabel 1) dengan kategori baik dan hasil uji coba ahli materi diperoleh persentase sebesar 88,6\% (tabel 2) termasuk dalam kategori sangat baik.

\begin{tabular}{|c|c|c|c|}
\hline No. & Indikator & $\begin{array}{l}\text { Rata-rata } \\
\text { Persentase }\end{array}$ & Kategori \\
\hline 1. & $\begin{array}{l}\text { Tampilan } \\
\text { Tulisan }\end{array}$ & \multirow{4}{*}{$82,9 \%$} & \multirow{4}{*}{ Baik } \\
\hline 2. & Desain & & \\
\hline 3. & $\begin{array}{l}\text { Tampilan } \\
\text { Gambar }\end{array}$ & & \\
\hline 4. & $\begin{array}{l}\text { Fungsi } \\
\text { Media }\end{array}$ & & \\
\hline \multicolumn{4}{|c|}{ Tabel 1 Hasil Validasi Ahli Media } \\
\hline No. & Indikator & $\begin{array}{l}\text { Rata-rata } \\
\text { Persentase }\end{array}$ & Kategori \\
\hline $\begin{array}{l}1 . \\
2 . \\
3 . \\
4 .\end{array}$ & $\begin{array}{l}\text { Isi } \\
\text { Konstruksi } \\
\text { Bahasa } \\
\text { Fungsi } \\
\text { Media }\end{array}$ & $88,6 \%$ & $\begin{array}{c}\text { Sangat } \\
\text { Baik }\end{array}$ \\
\hline
\end{tabular}

Tabel 2 Hasil Validasi Ahli Materi

Setelah melakukan uji validitas ahli, peneliti selanjutnya melakukan perbaikan media berdasarkan hasil masukkan dan saran yang diberikan oleh para ahli. Berikut perubahan media yang telah dilakukan: 


\begin{tabular}{|c|c|c|}
\hline Saran & Sebelum & Sesudah \\
\hline $\begin{array}{l}\text { Desain ulang } \\
\text { sampul buku }\end{array}$ & $\begin{array}{l}\text { Komposisi } \\
\text { warna pada } \\
\text { sampul } \\
\text { buku } \\
\text { kurang } \\
\text { sesuai } \\
\text { dengan } \\
\text { tema }\end{array}$ & $\begin{array}{l}\text { Desain } \\
\text { sampul buku } \\
\text { berubah, } \\
\text { disesuaikan } \\
\text { dengan tema } \\
\text { buku }\end{array}$ \\
\hline $\begin{array}{l}\text { Tambahkan } \\
\text { penjelasan } \\
\text { pengguna } \\
\text { buku }\end{array}$ & $\begin{array}{l}\text { Tidak } \\
\text { terdapat } \\
\text { penjelasan } \\
\text { pengguna } \\
\text { buku }\end{array}$ & $\begin{array}{l}\text { Pada sampul } \\
\text { buku tersedia } \\
\text { judul kecil } \\
\text { yang } \\
\text { memberikan } \\
\text { ciri bahwa } \\
\text { pengguna } \\
\text { buku adalah } \\
\text { remaja }\end{array}$ \\
\hline $\begin{array}{l}\text { Tambahkan } \\
\text { tujuan pada } \\
\text { awal buku } \\
\text { agar pembaca } \\
\text { mengetahui } \\
\text { isi buku } \\
\text { secara } \\
\text { keseluruhan }\end{array}$ & $\begin{array}{l}\text { Tidak } \\
\text { terdapat } \\
\text { penjelasan } \\
\text { tujuan pada } \\
\text { awal buku }\end{array}$ & $\begin{array}{l}\text { Terdapat } \\
\text { tujuan awal } \\
\text { buku sebagai } \\
\text { pembuka agar } \\
\text { pembaca } \\
\text { mengetahui } \\
\text { isi yang akan } \\
\text { dibahas pada } \\
\text { buku }\end{array}$ \\
\hline
\end{tabular}

Tabel 3 Perubahan Media

\begin{tabular}{lll}
\hline \multicolumn{1}{c}{ Saran } & \multicolumn{1}{c}{ Sebelum } & Sesudah \\
\hline $\begin{array}{l}\text { Tulisan yang } \\
\text { terlalu rapat } \\
\text { dipisahkan }\end{array}$ & $\begin{array}{l}\text { Beberapa } \\
\text { tulisan terlalu } \\
\text { rapat }\end{array}$ & $\begin{array}{l}\text { Beberapa } \\
\text { tulisan } \\
\text { yang rapat } \\
\text { diberi } \\
\text { jarak agar } \\
\text { sesuai }\end{array}$ \\
& & Beberapa \\
& & tulisan \\
Bahasa yang & Beberapa & yang \\
terlalu & tulisan & terlalu \\
panjang & menggunakan \\
diefektifkan & bahasa yang \\
& terlalu panjang & diringkas \\
& & agar \\
& & efektif \\
\hline
\end{tabular}

Tabel 4 Perubahan Materi

Dalam penerapannya, peneliti tidak melalui tahap uji coba pilot. Sebab dalam pelaksanaannya, media self-help book memerlukan waktu yang cukup banyak untuk mengetahui keefektifannya. Hal ini kemudian peneliti masukkan pada keterbatasan penelitian. Namun demikian, peneliti melakukan uji coba kelayakan produk kepada 10 peserta didik dan diperoleh hasil persentase sebanyak 91\% (tabel 3) termasuk dalam kategori sangat baik.

\begin{tabular}{cccc}
\hline No. & Indikator & $\begin{array}{c}\text { Rata-rata } \\
\text { Persentase }\end{array}$ & Kategori \\
\hline 1. & Ketertarikan & $91 \%$ & $\begin{array}{c}\text { Sangat } \\
\text { Baik }\end{array}$ \\
\hline
\end{tabular}

Tabel 4 Hasil Uji Kelayakan Peserta Didik

Berdasarkan hasil evalausi formatif pada tahap pengembangan tersebut, maka media self-help book untuk membantu peserta didik mengatasi konflik dengan orang tua dapat dikategorikan baik dan dapat digunakan oleh guru BK sebagai media layanan responsif dalam kegiatan konseling individu atau kelompok.

Penelitian pengembangan ini memiliki beberapa keterbatasan yang masih harus diperbaiki agar dapat dipergunakan secara maksimal oleh peserta didik dalam mengatasi konflik dengan orang tua. Beberapa keterbatasan itu meliputi: (1) penelitian ini hanya sampai pada tahap pengembangan; (2) angket studi pendahuluan dan proses identifikasi peserta didik yang berkonflik tidak menggunakan perspektif realitas; (3) penyusunan teori dalam pengembangan media masih belum berurutan; (4) penelitian ini tidak melakukan uji coba pilot.

\section{KESIMPULAN}

Hasil penelitian pengembangan media self-help book untuk membantu peserta didik mengatasi konflik dengan orang tua memiliki kesimpulan bahwa self-help book merupakan media yang dapat dikembangkan untuk mengajak peserta didik merencanakan tindakan efektif dalam mengatasi konflik dengan orang tua melalui tahapan-tahapan yang didasari oleh sistem WDEP dalam perspektif realitas. Pengembangan media 
self-help book untuk membantu peserta didik mengatasi konflik dengan orang tua di SMA Suluh Jakarta telah memenuhi komponen yang baik.

Penelitian ini dilakukan dengan menggunakan metode Research and Development (RnD) berbasis pengembangan dengan menggunakan metode ADDIE. Dalam penelitian ini, peneliti hanya melakukan tahap analisis, desain, dan pengembangan sebab penelitian ini hanya sampai pada penyempurnaan produk dengan waktu yang cukup terbatas.

Spesifikasi media ini dilengkapi dengan isi materi berupa tahapan penyelesaian konflik, gambar ilustrasi, tata letak, jenis kertas yang menarik, dan warna yang berbeda pada setiap bab untuk menunjang penyampaian informasi agar menarik perhatian peserta didik.

Evaluasi yang digunakan pada penelitian ini adalah evaluasi formatif dengan melakukan uji validitas kepada ahli media, ahli materi, dan peserta didik menggunakan kuesioner berupa angket. Berdasarkan evaluasi yang sudah dilakukan, validasi media oleh dosen Teknologi Pendidikan mencapai angka 82,9\% yang berarti baik. Validasi konten atau materi oleh dosen Bimbingan dan Konseling mencapai angka $88,6 \%$ yang berarti sangat baik. Sedangkan, hasil penilaian yang dilakukan kepada peserta didik mencapai angka 91,9\% yang berarti sangat baik.

Dari hasil penilaian tersebut, terdapat beberapa keunggulan dan kelemahan pada media self-help book menurut para ahli. Keunggulan media ini adalah variasi warna yang mengundang pembaca untuk membaca dan menghindari kejenuhan, alur tulisan informal cocok dengan sasaran pembaca, bahasa yang digunakan ringan, dan tersedia contoh kasus serta testimoni yang cukup banyak. Adapun kelemahan pada media ini berupa sampul buku yang tidak sesuai dengan tema layout buku serta ada beberapa tulisan yang perlu diberi jarak.

Masukkan dan saran untuk media ini adalah perlu dilakukan desain ulang pada sampul buku yang disertai judul kecil berupa petunjuk bagi remaja agar mereka mengetahui bahwa buku ditujukan kepada mereka dan beberapa tulisan yang terlalu rapat peneliti beri jarak. Sehingga, langkah selanjutnya peneliti melakukan perbaikan agar media dapat digunakan peserta didik sesuai dengan masukkan dan saran para ahli.

Sehingga, saran untuk penelitian ini adalah: (1) penelitian ini dapat dilanjutkan sampai tahap evaluasi; (2) perlu adanya perbaikan pada pernyataan studi pendahuluan; (3) dalam pengembangan konten, perlu dilakukan perbaikan komposisi secara berurutan dalam penggunaan teori; (3) penelitian ini dapat diteruskan dengan melakukan uji coba pilot untuk mengetahui keefektifan media.

\section{DAFTAR PUSTAKA}

Aldoobie, N. (2015). ADDIE Model. American International Journal of Contemporary Research, 5(6), 68-72.

Allison, B. N. (2000). Parent-Adolescent Conflict in Early Adolescent: Research and Implications for Middle School Programs. Journal of Family and Consumer Sciences Education, 18(2), 1-6.

Bergsma, A. (2007). Do Self-Help Book Help? Springer, 9(1), 341-360.

Borg, W. R., \& Gall, M. G. (1989). Educational Research: An Introduction, Fifth Edition. New York: Longman.

Branch, R. M. (2009). Instructional Design: The ADDIE Approach. New York: Springer Science + Bussiness Media.

Corey, G. (2013). Teori dan Praktek Konseling dan Psikoterapi. Bandung: PT Refika Aditama.

Corey, G. (2013). Theory and Practice of Counseling and Psychotherapy. United Stated of America: Brooks/Cole, Cengage Learning.

Deutsch, M., Coleman, P. T., \& Marcus, E. C. (2016). Handbook Resolusi Konflik. Bandung: Nusamedia. 
Fitzgerald, A. L. (2011). Reality Therapy for Marital and Family Systems Counseling. Counseling and Wellness: A Professional Counseling Journal, $2(1), 88-100$.

Frydenberg, E. (2002). Adolescent Coping: Theoretical and Research Perspectives. New York: Routledge.

Frydenberg, E., \& Lewis, R. (1991). Adolescent Coping: the Different Ways in which Boys and Girls Cope. Journal of Adolescent, 14(2), 119-133.

Gall, M. D., Gall, J. P., \& Borg, W. R. (2003). Educational Research An Introduction. United States of America: Pearson Education.

Gecas, V. (1982). The Self Concept. Annual Reviews, 8(1), 1-33.

Gunarsa, P. S. (2012). Konseling dan Psikoterapi. Jakarta: Libri.

Lestari, S. (2012). Psikologi Keluarga. Jakarta: Kencana.

Lestari, S. (2012). Psikologi Keluarga: Penanaman Nilai dan Penanganan Konflik dalam Keluarga. Jakarta: Kencana Prenada Media Group.

Lestari, S., \& Asyanti, S. (2009). Area Konflik Remaja Awal Dengan Orang Tua: Studi Kuantitatif Pada Keluarga Di Surakarta. Jurnal Penelitian Humaniora.

Palmer, S. (2011). Konseling dan Psikoterapi. Yogyakarta: Pustaka Belajar.

Razali, A. (2013). Child-Parent Conflict and its Impact on Adolescent SelfDevelopment. Asian Journal of Humanities and Social Studies, 1(5), 345-353.

Sugiyono. (2014). Metode Penelitian Kuantitatif Kualitatif dan $R \& D$. Bandung: Alfabeta.

Sugiyono. (2017). Metode Penelitian dan Pengembangan. Bandung: Alfabeta. 